\title{
Numerical Investigation of Condensation in Inclined Tube Air-cooled Condensers
}

\author{
Kaipo Kekaula ${ }^{\mathrm{a}}$, Yitung Chen ${ }^{\mathrm{a}, *}$, Ting Ma ${ }^{\mathrm{b}}$, Qiu-wang Wang ${ }^{\mathrm{b}}$ \\ ${ }^{a}$ Department of Mechanical Engineering, University of Nevada, Las Vegas, 4505 Maryland Parkway, Box 454027, Las \\ Vegas, NV 89154-4027, United States \\ ${ }^{\mathrm{b}}$ Key Laboratory of Thermo-Fluid Science and Engineering, MOE, Xi'an Jiaotong University, Xi'an, Shaanxi 710049, \\ China \\ *Corresponding Author: Yitung.Chen@unlv.edu
}

\begin{abstract}
Air-cooled condensers (ACC) have the potential to drastically reduce water consumption in power plants using a steam Rankine cycle operating; however, there are very few comprehensive models to simultaneously describe the heat and mass transfer effects for both the air and steam domains. This paper presents a coupled model for laminar film condensation and air side convective cooling for an inclined air cooled condenser tube. The air-side fluid flow is modeled using ANSYS Fluent. A Nusselt thin film analysis is then used to describe the film thickness in the upper region of the tube interior with a pool condensation model used to define the axial flow in the lower region. The commonly used isothermal boundary condition is relaxed by applying the heat transfer at the tube surface on the air-side to the inside tube surface during the film analysis to investigate the impact on the local film thickness and the overall heat transfer coefficient of the condenser. The results are related to the heat transfer on both staggered and inline tube configurations.
\end{abstract}

Keywords: Air-cooled Condensers, Multiphase Flow, Condensation, Heat Exchanger

(C) 2016. This manuscript version is made available under the Elsevier user license

http://www.elsevier.com/open-access/userlicense/1.0/ 


\section{INTRODUCTION}

The heat and mass transfer phenomena in dry cooling are important in many applications including refrigeration, power generation and electronics cooling systems. Due to increased water conservation efforts, air-cooled steam condensers, also known as dry cooling systems, have been the topic of many investigations in the energy sector. Direct dry cooling has been shown to reduce the water consumption of a concentrated solar power plant by over 90 percent when compared to a more traditional wet cooling.

Almost all analyses involving film condensation inside or outside tubes can be traced back to the founding work by Nusselt [1]. The thin film assumption is broadly used in nearly all film condensation models. Condensation on inclined tubes was studied analytically by Fieg and Roetzel [2] using thin film theory along the upper regions of cylinders. This, however, was unable to account for the accumulation on the lower regions of the domain. To remedy this, Chato [3] proposed splitting the domain into two regions, the upper thin condensate film region and the accumulated flow region along the lower part of the cylinder separated by the stratification angle, $\phi_{\mathrm{s}}$.Wang and Du [4] proposed using an arc shaped interface for the lower accumulation region. Rose et al. [5] was one of the few papers to stray from the most commonly used isothermal boundary condition when calculating the film condensation in and on circular tubes assuming a cosine temperature distribution on the tube surface.

Cross-flow over cylindrical tubes have also been extensively studied in the literature over isolated cylinders as well as cylinder tube banks [6-9]. There have been many numerical and empirical studies of the heat transfer on cylinders. Due to the large variation in the local heat transfer coefficient around the tube and the volatility associated with the detached turbulent region, there have been many experimental and numerical studies to characterize the flow. Numerical models were initially based on steady state conditions for low Reynolds numbers. Krall and Eckert [10] provided one of the earlier experimental investigations of the local heat transfer characteristics of cylinders in crossflow. Chun and Boehm [11] provided a numerical analysis of the local heat transfer on a plane circular tube with cross flow using a symmetric steady grid. In a later paper, the same authors determined that a non-isothermal boundary condition could be significantly affect the results.

\section{THEORY}

\subsection{Physical Problem}

In the conventional A-frame air-cooled steam condenser, steam enters the system in an upper steam manifold. The steam is then divided into inclined heat exchanger tubes where the heat is removed by ambient air which is pulled from the lower end of the system by a fan and blown up and over the tubes. This system is shown in Fig. 1. The problem specified can be described mathematically as film condensation in a cylindrical tube with the air-side cross flow travelling perpendicular to the steam direction upwards over the tube. 


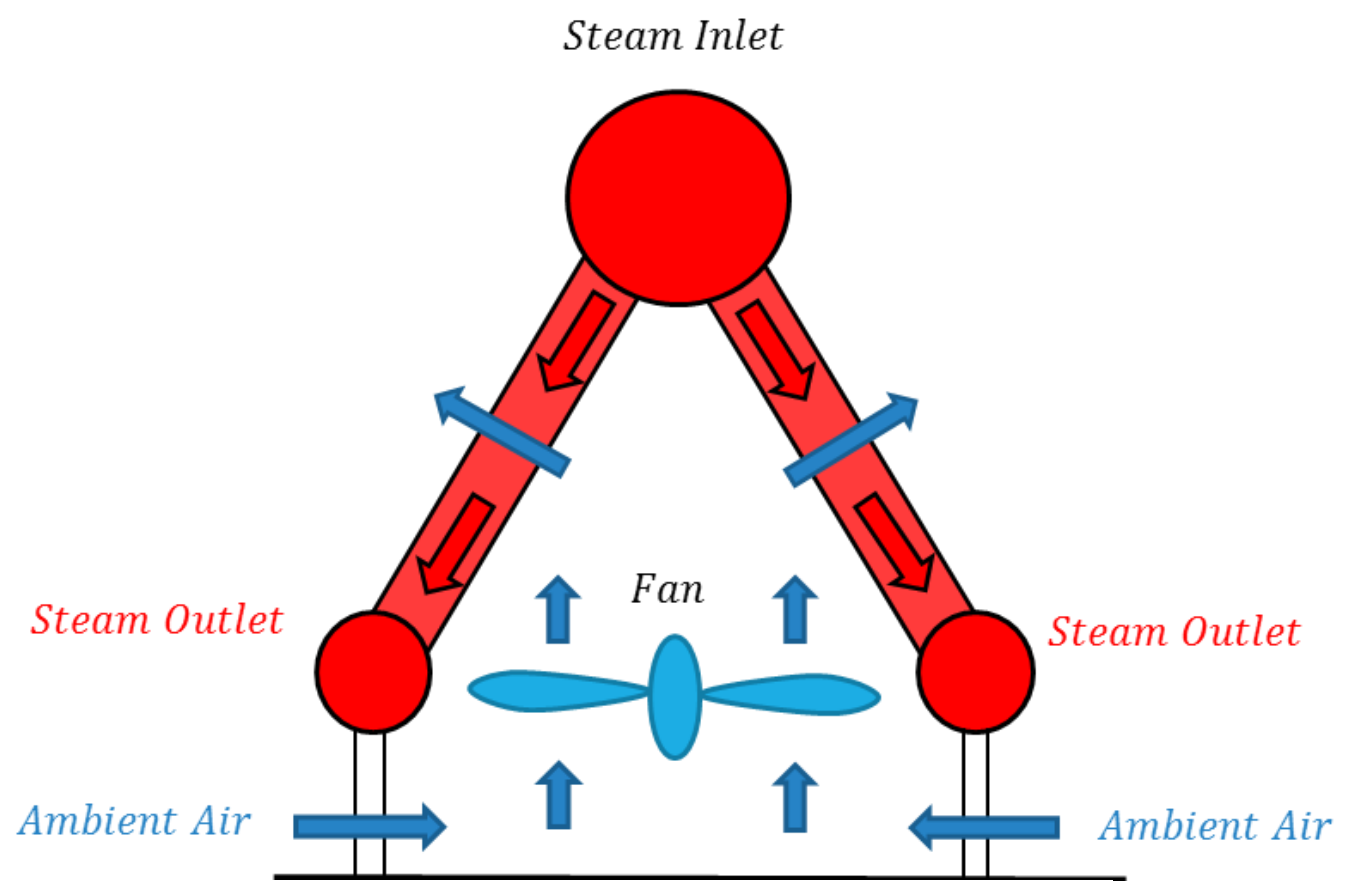

FIG. 1. Schematic of A-frame air-cooled steam condenser

\subsection{Multiphase Model}

First consider the condensation flow inside the condensation tubes. Pure steam enters at the top of the condenser and flows axially along the interior of the tube. As the steam is cooled, condensate forms along the upper surface. This forms a film flowing downwards under the influence of gravity. The tube is inclined at angle $\beta$ and has diameter D. Curvilinear coordinates are used for this system with the geometry shown in Fig. 2. Crossflow convective heat transfer cools the tube exterior with air as the working fluid.

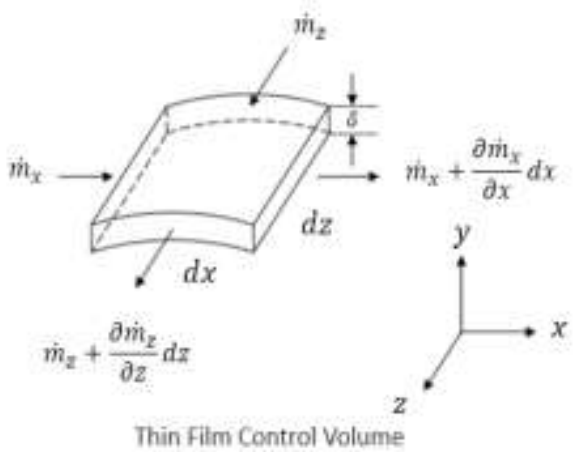




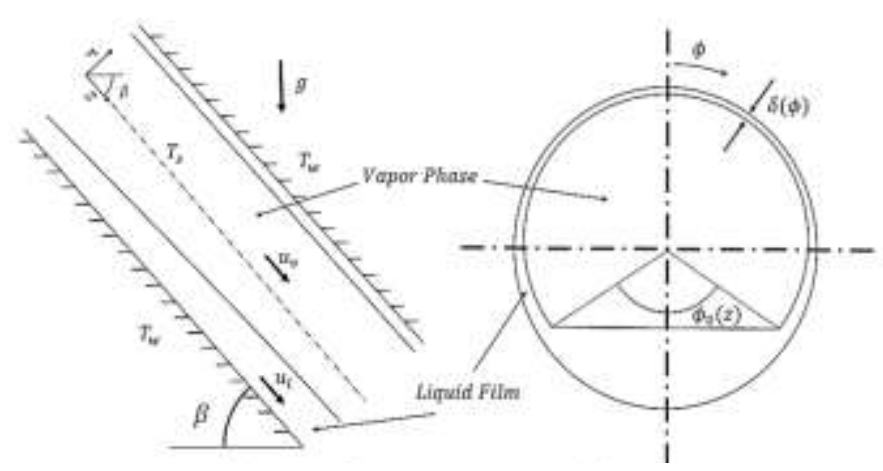

FIG. 2. Inclined laminar film condensation with accumulation

\subsubsection{Governing Equations}

The problem under consideration can be described as the condensation of a pure vapor in a tube that is inclined from the horizontal at an angle $\beta$ from the horizontal. The wall temperature is assumed to be lower than the saturation temperature of the steam; therefore, condensation will occur on the tube walls. The condensed liquid flows downwards under the influence of gravity. In addition to the previously outlined simplifications, the following assumptions per the classic Nusselt film theory are:

- The liquid film thickness in the upper region of the tube is much smaller than the tube diameter $(\delta \ll D)$.

- The acceleration terms in the momentum equation can be neglected.

- The temperature distribution in the film layer is linear.

- The liquid condensate flow is assumed to be smooth and laminar.

- The shear stress on the liquid film is negligible.

- The condensed liquid has axial and tangential components but does not move radially.

The $\mathrm{x}$ - and $\mathrm{z}$-momentum equations can be then expressed as:

$$
\begin{gathered}
\mu_{l} \frac{\partial^{2} u}{\partial y^{2}}+\left(\rho_{l}-\rho_{v}\right) g \sin \phi \cos \beta=0 \\
\mu_{l} \frac{\partial^{2} w}{\partial y^{2}}+\left(\rho_{l}-\rho_{v}\right) g \sin \beta=0
\end{gathered}
$$

The boundary conditions for the momentum equations have a no slip boundary condition is applied at the tube wall and interfacial shear is zero at the vapor-liquid interface.

$$
\begin{gathered}
y=0: u=w=0 \\
y=\delta: \frac{\partial u}{\partial y}=\frac{\partial w}{\partial y}=0
\end{gathered}
$$

Integrating the momentum equations and applying the boundary conditions yields equations for the velocity components in both the axial and tangential directions: 


$$
\begin{gathered}
u=\frac{g\left(\rho_{l}-\rho_{v}\right) \sin \phi \cos \beta}{\mu_{l}} \delta^{2}\left(\frac{y}{\delta}-\frac{1}{2}\left(\frac{y}{\delta}\right)^{2}\right) \\
w=\frac{g\left(\rho_{l}-\rho_{v}\right) \sin \beta}{\mu_{l}} \delta^{2}\left(\frac{y}{\delta}-\frac{1}{2}\left(\frac{y}{\delta}\right)^{2}\right)
\end{gathered}
$$

Integration of the continuity equation over the film thickness and incorporating the phase change at the interface gives:

$$
\frac{\partial}{\partial x} \int_{0}^{\delta} u d y+\frac{\partial}{\partial z} \int_{0}^{\delta} w d y=\left(\frac{\lambda_{l}}{\rho_{l} H_{f g}}\right)\left(\frac{\partial T}{\partial y}\right)_{y=\delta}
$$

The temperature gradient at the interface is approximated using a heat transfer resistance analogy.

$$
\left(\frac{\partial T}{\partial y}\right)_{y=\delta}=\frac{T_{s a t}-T_{a m b}}{\frac{D}{N u_{a} \lambda_{a}}+\frac{\delta}{\lambda_{l}}}
$$

Substituting Eqs. (5), (6), and (8) into Eq. (7) and expressing the result in non-dimensional form gives the film thickness equation as:

$$
\cos \beta \sin \phi \delta^{* 2} \frac{\partial \delta^{*}}{\partial \phi}+\sin \beta \delta^{* 2} \frac{\partial \delta^{*}}{\partial \bar{z}}+\frac{2}{3} \cos \beta \cos \phi \delta^{* 3}=\frac{J a}{R a}\left(\frac{1}{\frac{r}{N u_{\text {air }}}+\delta^{*}}\right)
$$

Such that:

$$
\frac{J a}{R a}=\frac{\lambda_{l}\left(T_{\text {sat }}-T_{w}\right) \mu_{l}}{H g \rho_{l}\left(\rho_{l}-\rho_{v}\right) D^{3}}
$$

Once the film thickness equation is solved, the stratified angle can be calculated using a mass balance on the lower region of the tube assuming a rectangular cross-section. The mass flow rate change with respect to the $\mathrm{z}-$ direction can be given as:

$$
\frac{d \dot{m}_{l}}{d z}=\frac{2 \rho_{l}\left(\rho_{l}-\rho_{v}\right) g}{\mu_{l}} \sin \phi_{s} \cos \beta \delta^{3}\left(\phi_{s}\right)
$$

The overall heat transfer coefficient (HTC) can be calculated from the film thickness evaluated at the stratified angle, $\boldsymbol{\phi}_{s}$ :

$$
H T C=\frac{1}{\pi L} \int_{0}^{L} \int_{0}^{\phi_{s}}\left(\frac{D}{N u_{a} \lambda_{a}}+\frac{\delta}{\lambda_{l}}\right)^{-1} d \phi d z
$$

\subsection{Isolated Cylinder in Crossflow}



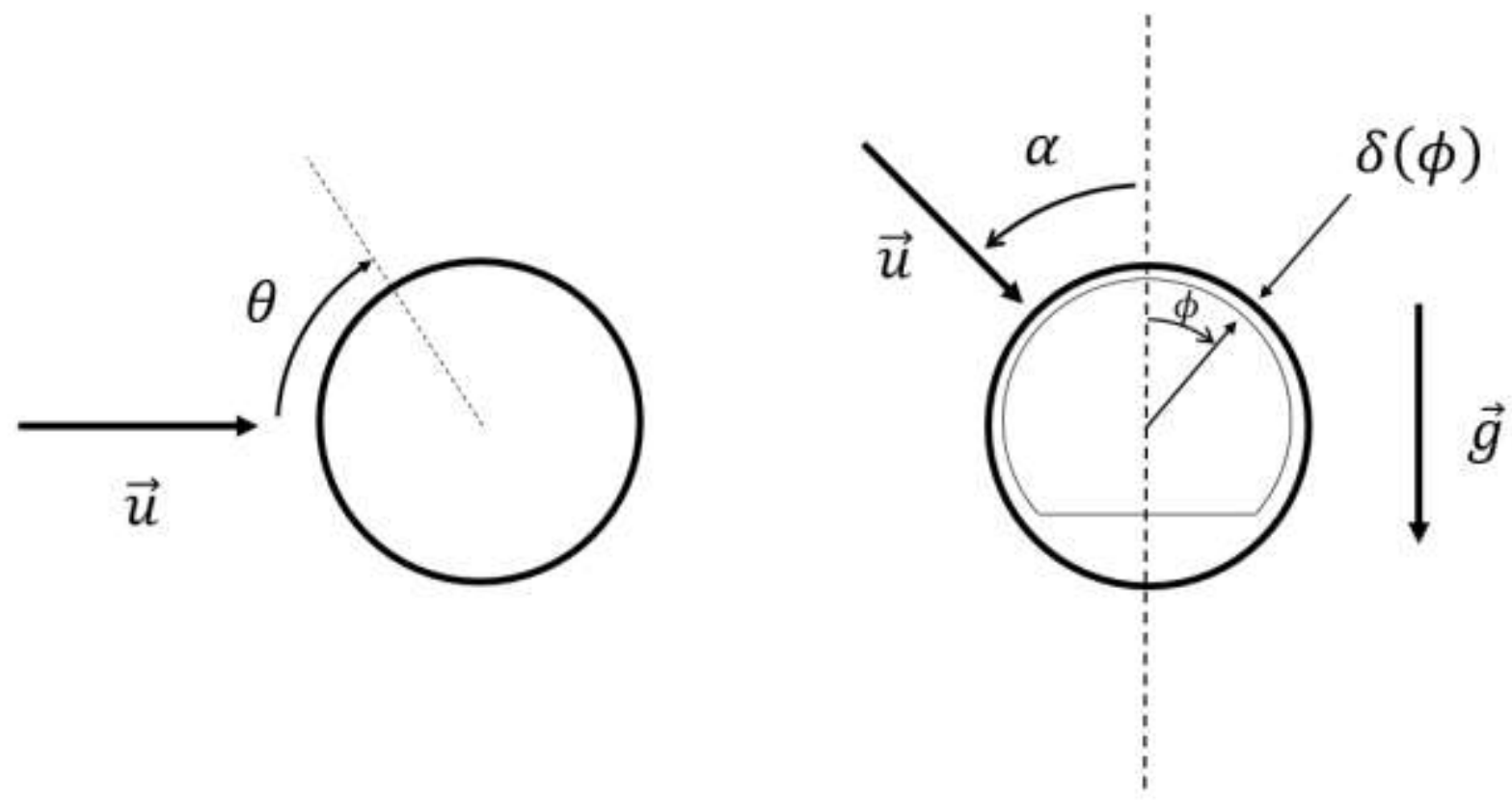

FIG. 3. Geometry for the angle relationships

While the Nusselt thin film analysis has proven to be an incredibly accurate model for film condensation in tubes for a wide range of parameters, the idealization of a constant surface temperature can become invalid if the coolant side resistance become large as is the case in air-cooled condensers. Therefore, the air side heat transfer characteristics must also be analyzed to get a comprehensive understanding of the system. Crossflow heat transfer over a circular cylinder can be used to approximate the physical situation and has been extensively studied both experimentally and numerically. The results show a significant non-uniformity in the heat transfer coefficient profile along the outside of the tube with the heat transfer coefficient being higher at the leading edge and lower near the point of separation. The tube surface temperature distribution and, consequently, the film thickness development along the tube wall are, therefore, strongly dependent on the flow direction as well as the relative magnitudes of the inner and outer heat transfer resistances.

Typically, the heat transfer on the coolant side in air-cooled condensers are significantly lower than the film thickness thermal resistance causing the surface temperature to approach the saturation temperature of the working fluid. This investigation used experimental data to represent the air side resistance where available and numerical models. The Nusselt number for crossflow over a tube varies as a function of the air-side angle, $\theta$, as measured from the leading edge as illustrated in Fig. 3. The measured air side Nusselt numbers from the literature [12] shown in Fig. 4 were coupled to the film thickness model to determine the consequences of the variable heat surface heat transfer coefficient on the air side as well as the role of the inclination and attack angle, $\alpha$. The relationships between the film thickness angle, $\phi$, angle of attack, $\alpha$, and air-side angle, $\theta$, are shown in Fig. 3. 


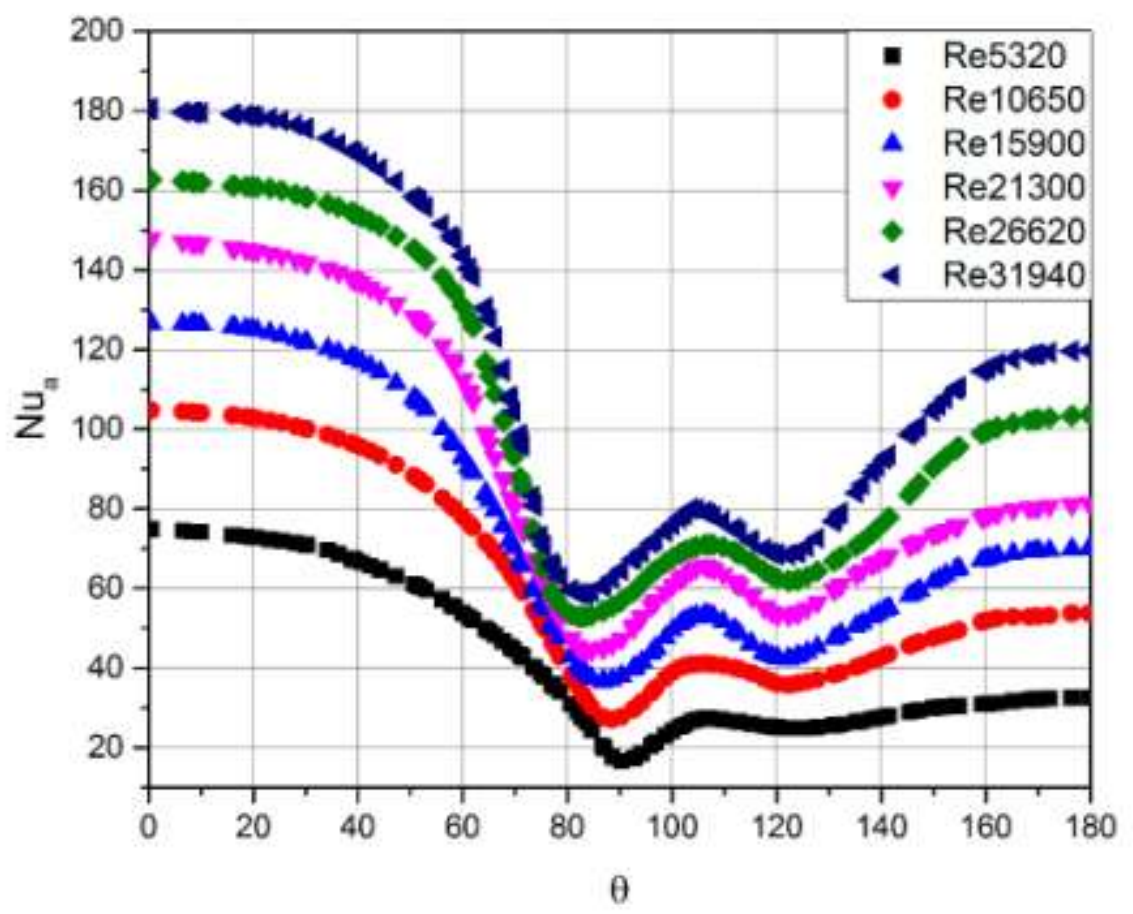

FIG. 4. Coolant heat transfer coefficient distribution for crossflow cooling. [12]

\subsection{CROSS FLOW OVER A TUBE BUNDLE}

While there is a large quantity of experimental data available for isolated cylinders, the data for tube bundles is largely limited to computational fluid dynamic (CFD) results and this is the method chosen for this portion of the study. The CFD simulation of the air side flow used ANSYS Fluent. The problem was assumed to be twodimensional, steady, incompressible, turbulent flow. The air was assumed to be Newtonian with constant physical properties. The staggered and in-line tube configurations and computational domains are shown in Fig. 5. A constant uniform velocity boundary condition is used at the inlet with a constant temperature, $\mathrm{T}_{\mathrm{amb}}$, with a pressure outlet at the opposite boundary. The upper and lower boundaries are symmetric. The tube surfaces are at constant temperature $\mathrm{T}_{\mathrm{w}}$.

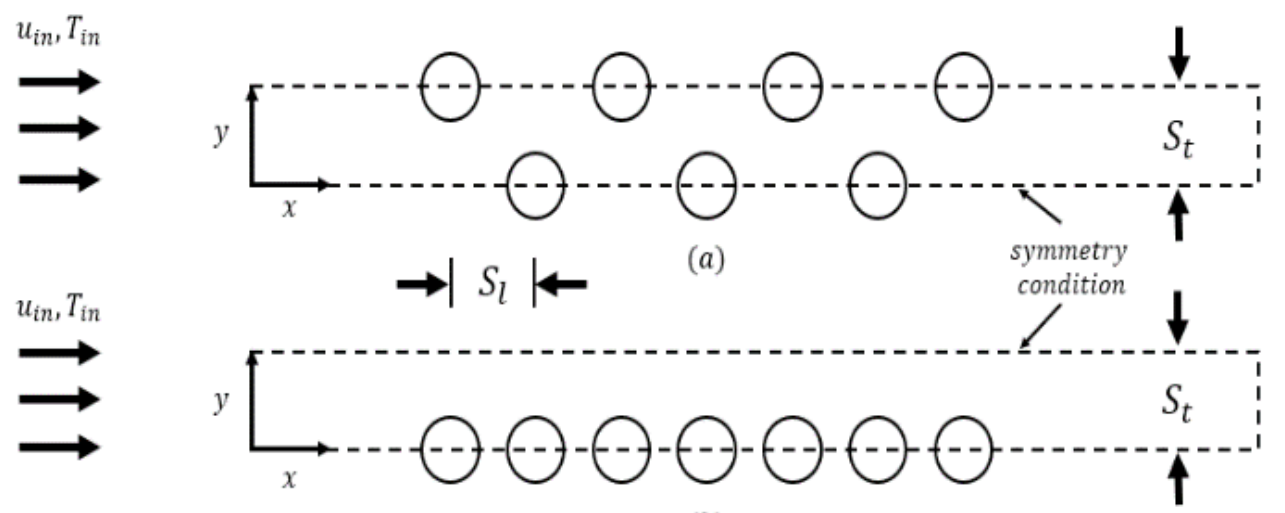

(b) 
FIG. 5. Computational Domain: (a) Staggered arrangement and (b) in-line arrangement

\begin{tabular}{ccc}
\hline Parameter & Value & \\
\hline$T_{w}$ & 373 & $\mathrm{~K}$ \\
$T_{a m b}$ & 300 & $\mathrm{~K}$ \\
$D$ & 10 & $\mathrm{~mm}$ \\
$L$ & 5000 & $\mathrm{~mm}$ \\
$R e$ & 2000,5000 & $\mathrm{~kg} / \mathrm{m}^{2}$ \\
$\rho$ & 1.225 & $\mathrm{deg}$ \\
$\beta$ & 45 & $\mathrm{~mm}$ \\
$S_{t}$ & 15 & $\mathrm{~mm}$ \\
$S_{l}$ & $15,20,25,30$ & $\mathrm{~Pa}$ \\
$p_{\text {out }}$ & 0 & \\
$(\text { Ra } / \mathrm{Ja})^{1 / 4}$ & 260 & \\
\hline
\end{tabular}

Table 1. Simulation Parameters

\subsubsection{Governing Equations}

The flow field in this problem was solved using a finite volume formulation to discretize the conservation equations for mass, momentum, and energy. The RANS (Reynolds-averaged Navier-Stokes) equations for the turbulent incompressible flow can be written in tensor notation as:

Continuity:

$$
\frac{\partial \rho}{\partial t}+\frac{\partial}{\partial x_{i}}\left(\rho u_{i}\right)=0
$$

Momentum:

$$
\frac{\partial}{\partial t}\left(\rho u_{i}\right)+\frac{\partial}{\partial x_{j}}\left(\rho u_{i} u_{j}\right)=-\frac{\partial p}{\partial x_{i}}+\frac{\partial}{\partial x_{j}}\left[\mu\left(\frac{\partial u_{i}}{\partial x_{j}}+\frac{\partial u_{j}}{\partial x_{i}}-\frac{2}{3} \delta_{i j} \frac{\partial u_{k}}{\partial x_{k}}\right)\right]+\frac{\partial}{\partial x_{j}}\left(-\rho \overrightarrow{u_{i}^{\prime} u_{j}^{\prime}}\right)
$$


Energy:

$$
\frac{\partial}{\partial x_{i}}\left[u_{i}(\rho E+p)\right]=\frac{\partial}{\partial x_{i}}\left[\lambda_{e f f} \frac{\partial T}{\partial x_{i}}+u_{j}\left(\tau_{i j}\right)_{e f f}\right]
$$

The RNG (Renormalization Group) k- $\epsilon$ turbulence model developed by Yakhot and Orzag [13] is used in this study. This is a two-equation model that improves upon the standard $\mathrm{k}-\epsilon$ model by adding an addition term to the $\epsilon$ equation that enhances the treatment of the swirl with an analytical formula for the turbulent Prandtl number.

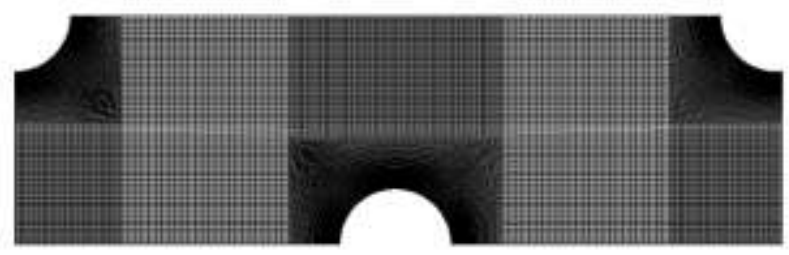

(a)

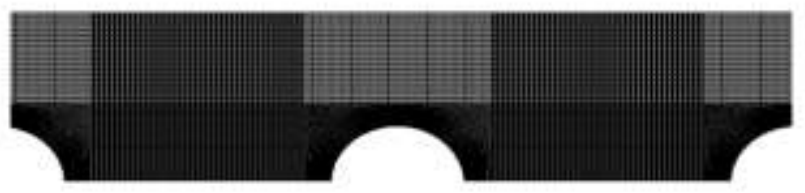

(b)

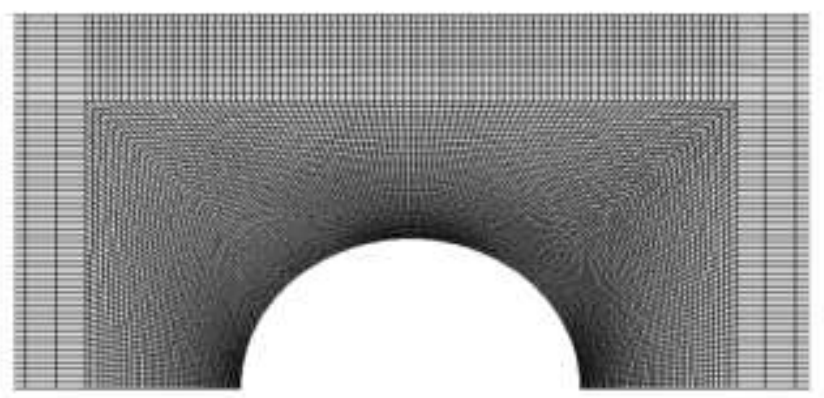

(c)

FIG. 6. Computational Mesh: (a) Staggered arrangement and (b) in-line arrangement (c) zoomed to the near wall mesh

\subsubsection{Grid Sensitivity}

To balance the computational expense and solution accuracy, a structured quadrilateral grid was used with local refinement near the surface of the cylinders to capture the boundary layer effects such as the steep temperature gradients. The computation meshes are shown in Fig. 6 . The influence of the grid refinement on the solution was investigated using several meshes with the grid densities shown in Table 1. The average Nusselt number on the leading and trailing cylinders were used as metrics with the relative error being less than $5 \%$ as is shown in Fig. 7. The refinement process investigated increasing the number of inflation layers near the cylinder surfaces as well as increasing the number of nodes around the periphery of the cylinder. The relative error in the average Nusselt number on the leading cylinder between Mesh E and F in Table 1 was less than 1\%; therefore, 
mesh E was selected for the analysis. Figures 8 and 9 compare the current numerical results for crossflow in tube banks to experiments by Zukauskas [14] and numerical results by Mirabdolah et al. [15]. The current results are in good agreement with the available experimental and numerical results.

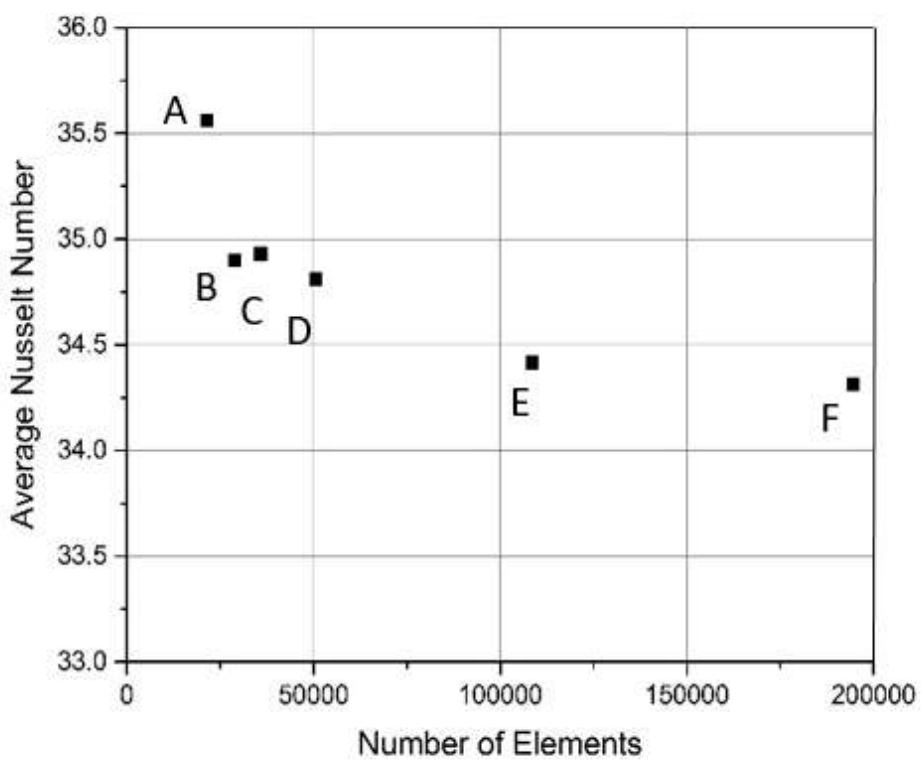

FIG. 7. Mesh Sensitivity Analysis

\begin{tabular}{cccc}
\hline Mesh & $\begin{array}{c}\text { Number of } \\
\text { inflation layers }\end{array}$ & $\begin{array}{c}\text { Cylinder } \\
\text { nodes }\end{array}$ & $\begin{array}{c}\text { Total } \\
\text { cells }\end{array}$ \\
\hline A & 15 & 80 & 21546 \\
B & 15 & 100 & 28857 \\
C & 25 & 100 & 35857 \\
D & 25 & 180 & 90564 \\
E & 40 & 180 & 118652 \\
F & 50 & 360 & 194587 \\
\hline
\end{tabular}

Table 2. Grid Independence Study 


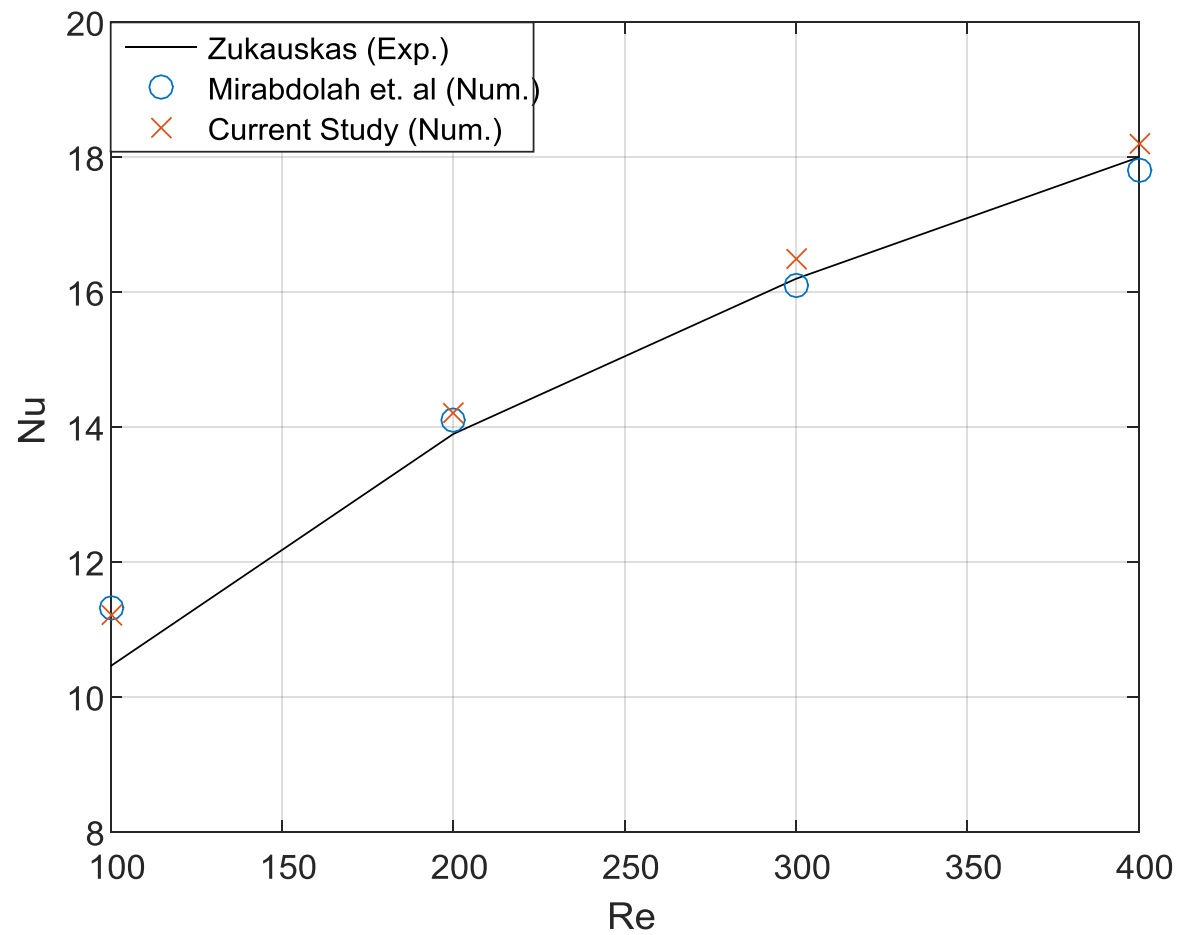

FIG. 8. Comparison of current results with experimental data for staggered configuration

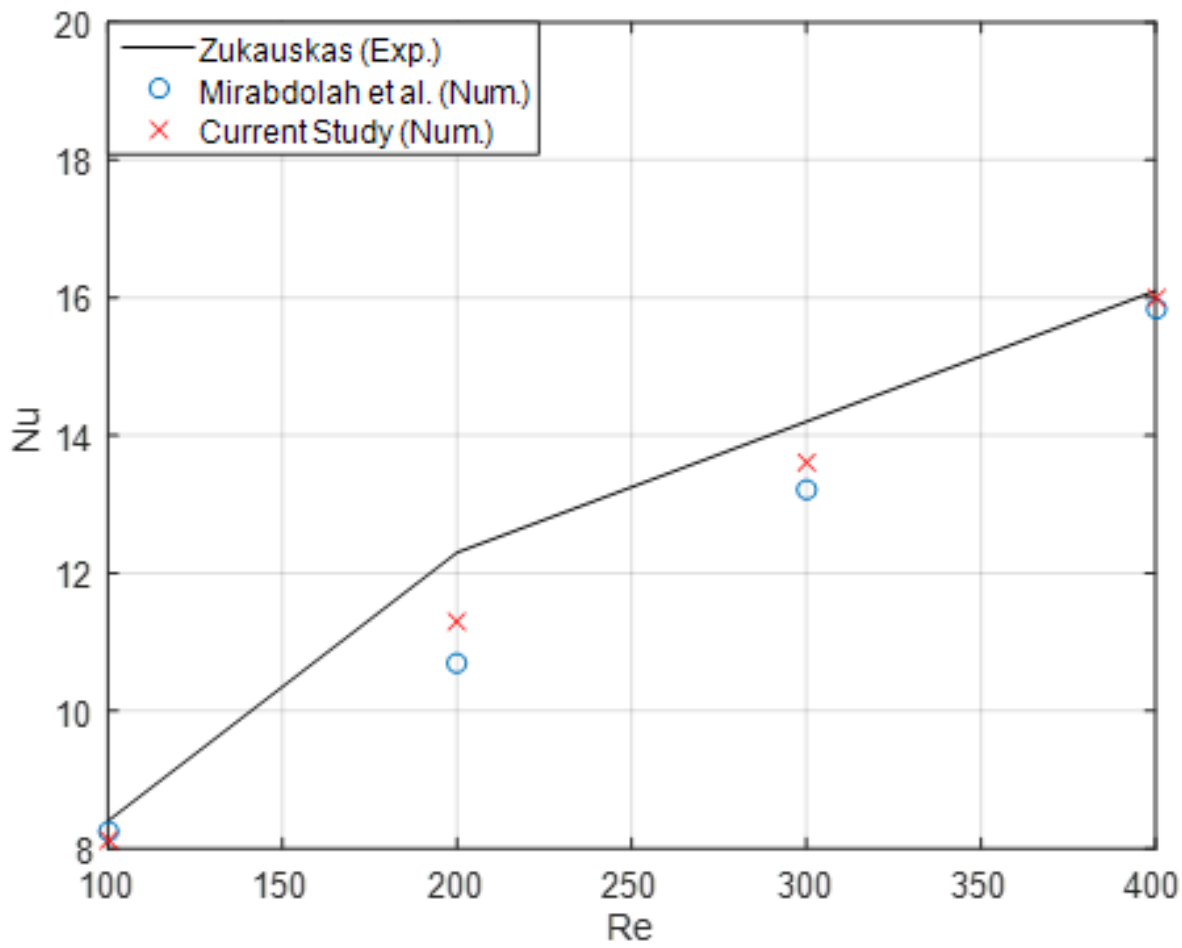

FIG. 9. Comparison of the current results with experimental data for the inline configuration 


\section{Results and Discussion}

This analysis considers film condensation inside the tubes with cross flow convective cooling across the tube bank. The coupling of a single isolated cylinder in a crossflow with the film condensation model in an inclined cylinder is investigated first. The cylinder is $2 \mathrm{~cm}$ in diameter with the measured air side local Nusselt number distributions shown in Fig. 4 for a range of coolant Reynolds number. The film thickness in the upper region of the steam domain of the tube is calculated by numerically solving Eq. (9). The film thickness is then used to iteratively determine the stratified angle for every axial position to characterize the accumulation in the lower portion of the tube. The stratified angle is shown in Fig. 10 as a function of the axial distance from the inlet for various coolant Reynolds numbers at a fixed inclination angle, $\beta$, of $75^{\circ}$. A higher Reynolds number yields a higher Nusselt number on the coolant side resulting in an increase in the accumulated condensate and a more rapid increase in the stratified angle.

The inclination angle significantly impacts the system heat transfer coefficient as a large inclination angle creates a larger driving force for the flow than a lower inclination angle where the flow is primarily tangential. For a constant coolant Reynolds number, the stratified angle for a range of inclination angles are shown in Fig. 11. As the inclination angle increases, the flow is driven axially under the influence of gravity which reduces the condensate accumulation at the lowermost point of the tube. The variations of the local Nusselt number along the axial direction for a constant inclination angle are shown in Fig. 12. For all the Reynolds numbers, the Nusselt number decreases with increasing axial position; however, a lower air side Reynolds numbers results in a more gradual decline due to less accumulation of the condensate in the lowermost region of the tubes.

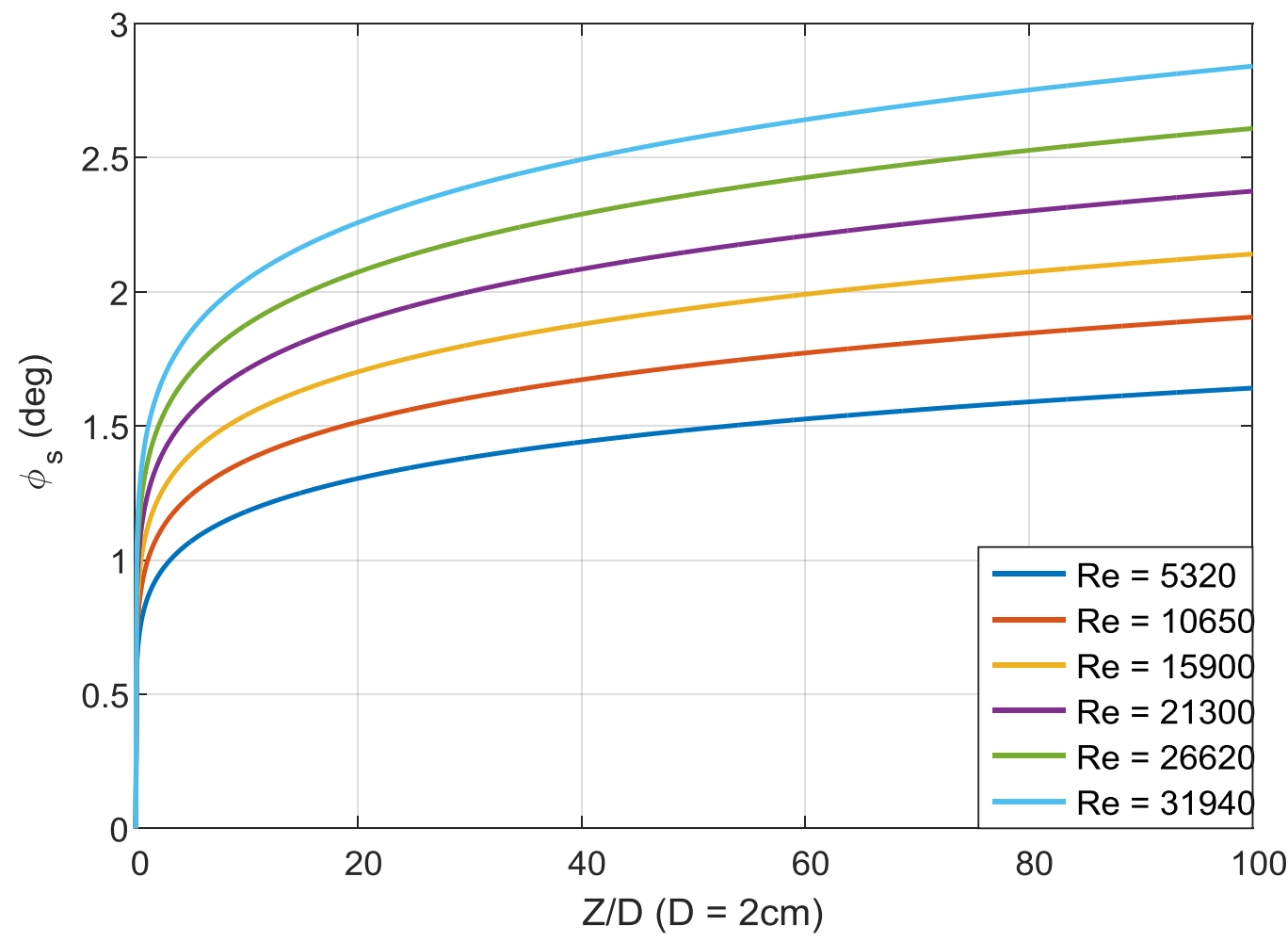

FIG. 10. Variation of the stratified angle with axial position for various coolant Reynolds numbers $\left(\boldsymbol{\beta}=\mathbf{7 5}^{\circ}\right)$ 


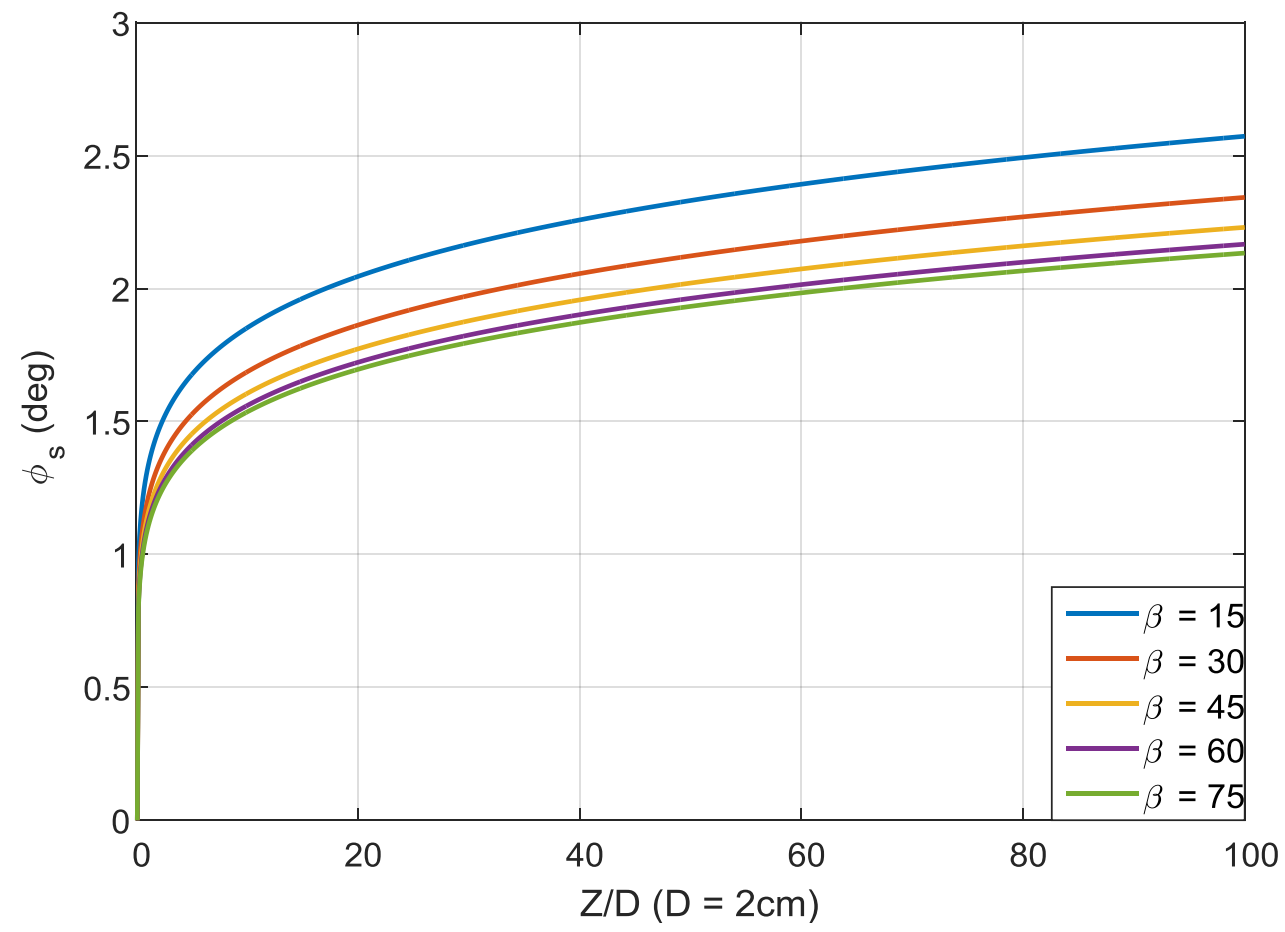

FIG. 11. Variation of the stratified angle with the axial position at various inclination angles $(\operatorname{Re}=15900)$

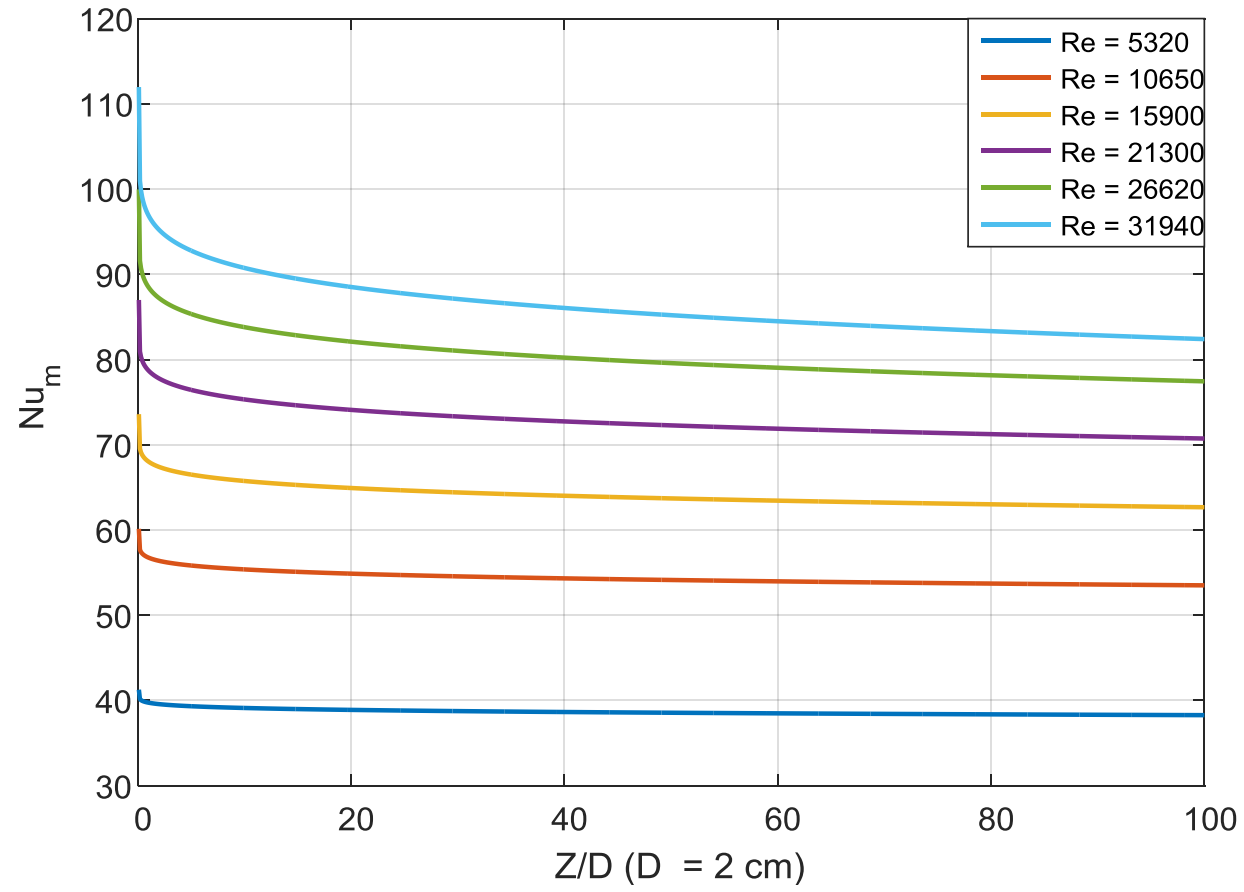

FIG. 12. Variation of the theoretical mean overall heat transfer coefficient with the coolant Reynolds number 


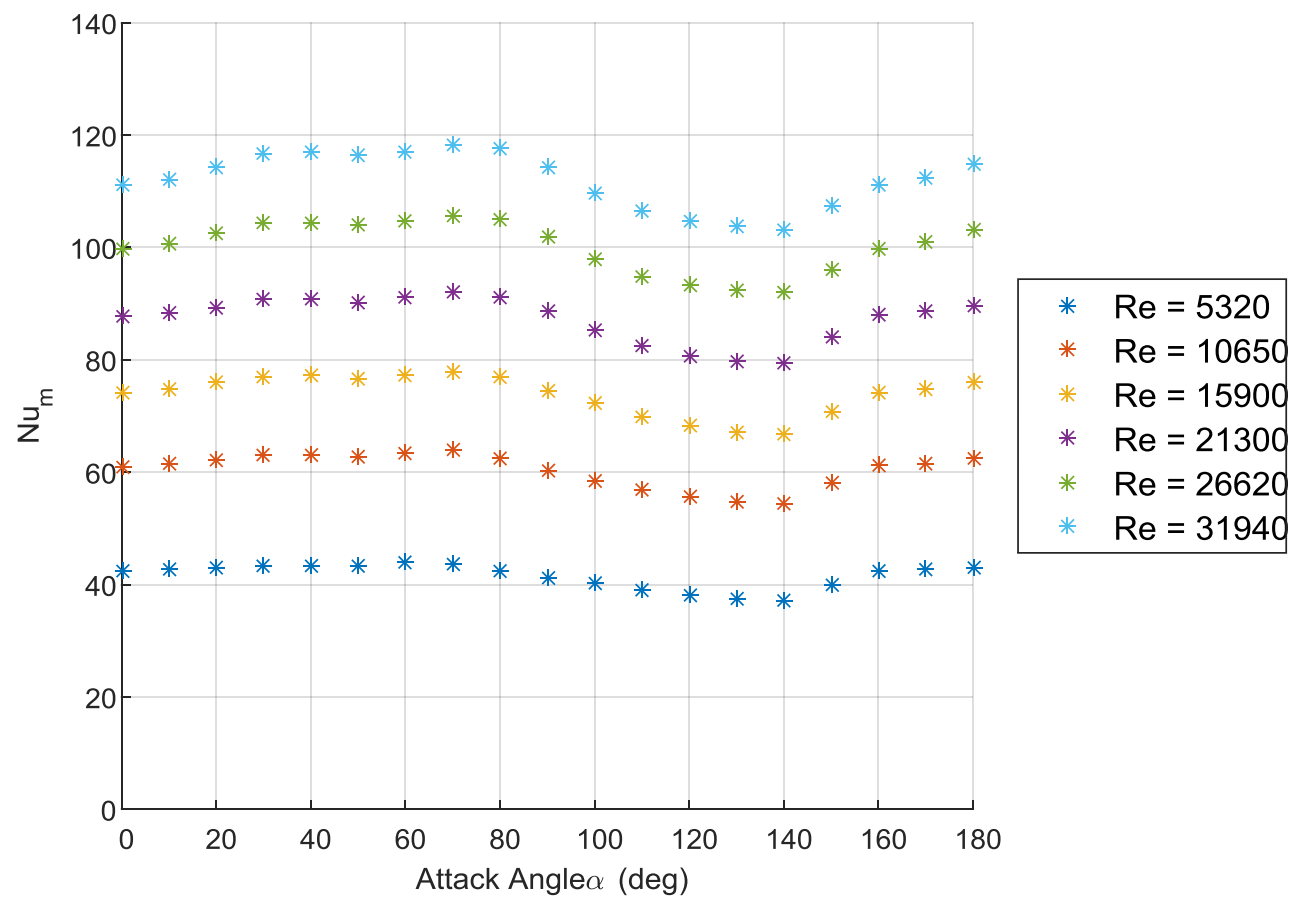

FIG. 13. Variation of the theoretical mean overall heat transfer coefficient with the coolant angle of attack, $\boldsymbol{\beta}=\mathbf{4 5}^{\circ}$

Due to the non-uniformity of the air side heat transfer coefficient, the flow direction can affect the condensation rate in the system. Figure 13 shows the dependence of the overall heat transfer coefficient on the attack angle for attack angles of $0^{\circ}$ and $180^{\circ}$ corresponding to the leading edge of the air crossflow located at the uppermost and lowermost points of the tube. The maximum Nusselt number occurs at an attack angle of $70^{\circ}$ from the uppermost point for an inclination angle of $45^{\circ}$. This effect becomes less pronounced as the inclination angle increases towards vertical $\left(\beta=90^{\circ}\right)$ due to the film condensate being driven axially under the influence of gravity.

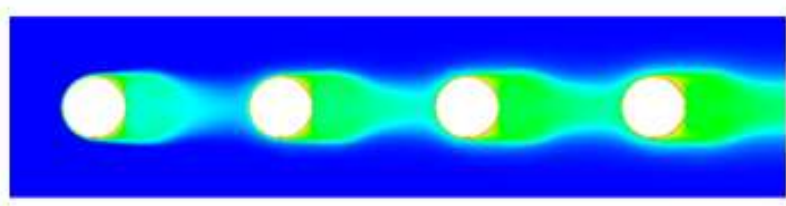

(a)
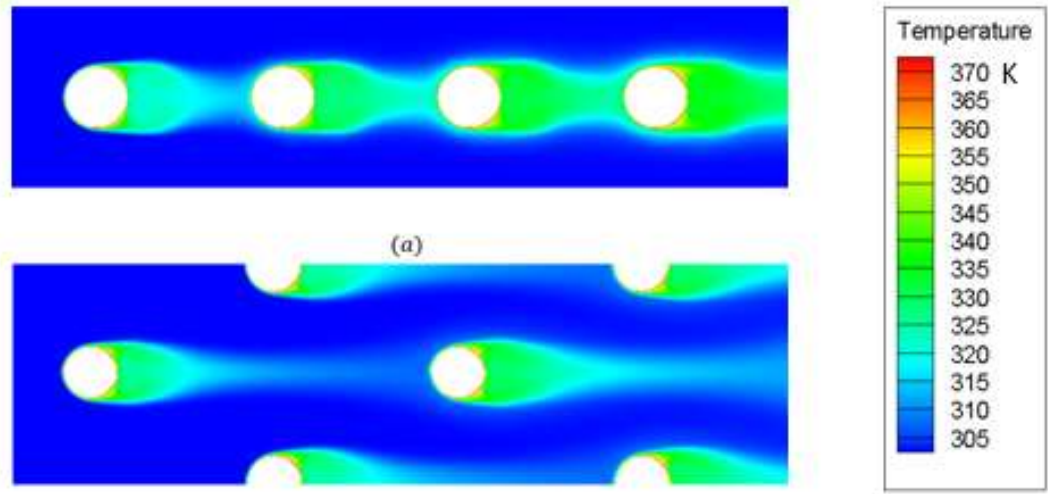

(b)

FIG. 14. Temperature Distribution for $\mathrm{Re}=2000 \quad S_{l}=\mathbf{2 5} \mathbf{~ m m}$ (a) Inline arrangement and (b) Staggered 


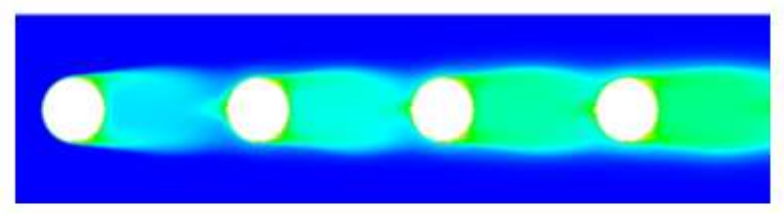

(a)

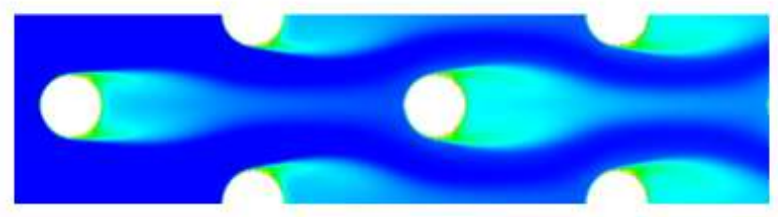

(b)

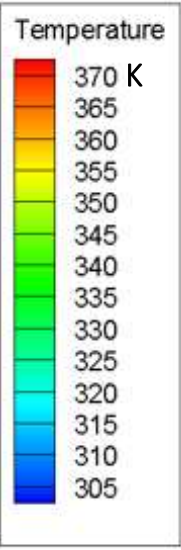

FIG. 15. Temperature Distribution for $\mathrm{Re}=5000 \quad S_{l}=\mathbf{2 5} \mathbf{~ m m}$ (a) Inline arrangement and (b) Staggered arrangement

The analysis of the heat transfer and condensation in tube bundles assumes that the air flow originates from the fan and approaches the bundle from the bottom, opposite to the direction of gravity; hence, the leading edge in the air side numerical simulation is at the lowermost point on the condensation tube and the trailing edge is at the uppermost point in the condensation domain. The heat transfer coefficient was calculated for each tube by combining the air side and steam side resistances for both the inline and staggered tube arrangements for $\mathrm{Re}=$ 2000 and $\operatorname{Re}=5000$ for various longitudinal pitches. 


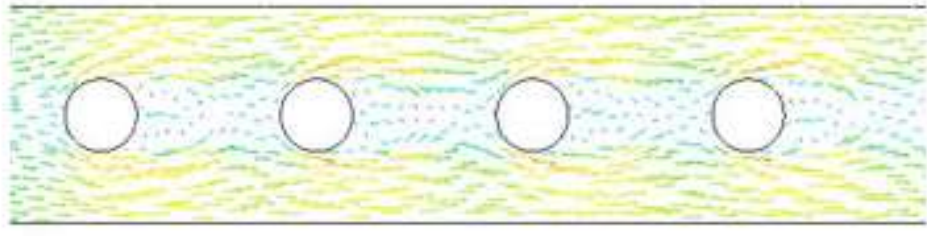

(a)

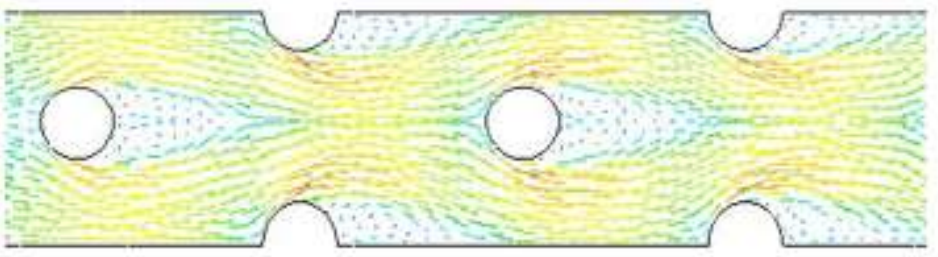

(b)

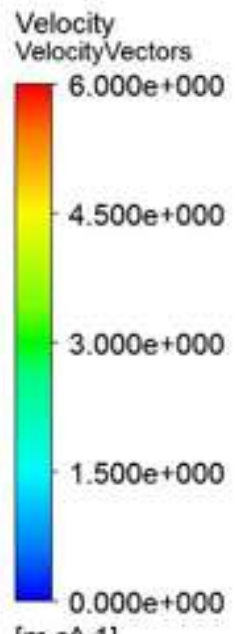

$\left[\mathrm{m} \mathrm{s}^{\wedge}-1\right]$

FIG. 16. Velocity Distribution for $\mathrm{Re}=2000$

$S_{l}=25 \mathrm{~mm}$

(a) Inline arrangement and (b) Staggered arrangement

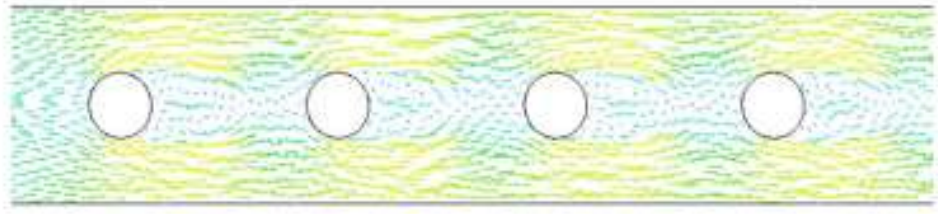

(a)

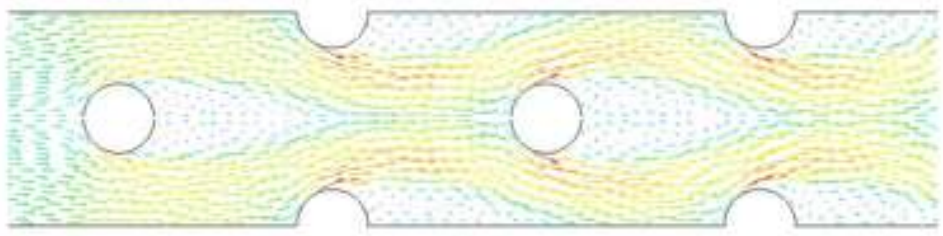

(b)

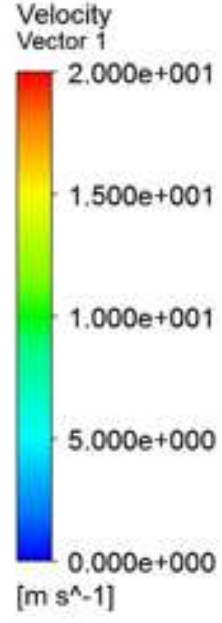

FIG. 17. Velocity Distribution for Re $=5000 S_{l}=\mathbf{2 5} \mathbf{~ m m}$ (a) Inline arrangement and (b) Staggered arrangement

The local Nusselt number on the air side was found using ANSYS Fluent for a range of longitudinal spacings and a fixed transverse spacing for both the staggered and inline configurations at Reynolds numbers of 2000 and 5000. Once calculated, the Nusselt number distributions were coupled to the interior flow using a heat transfer resistance analogy. The physical simulation parameters are shown in Table 2. Typical air side temperature and velocity distributions are shown Figs. 14-17 for both the inline and staggered tube arrangements. 


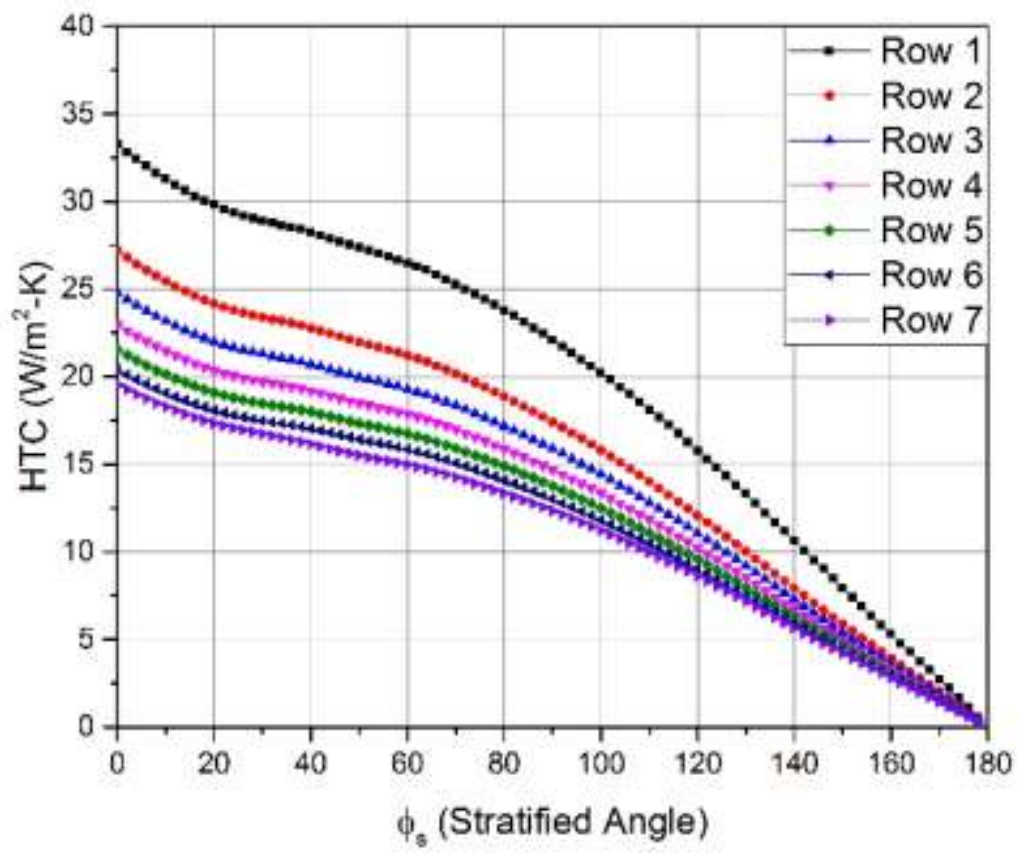

FIG. 18 Dependence of heat transfer coefficient on the stratified angle for $\mathrm{Re}=2000$ in an inline configuration.

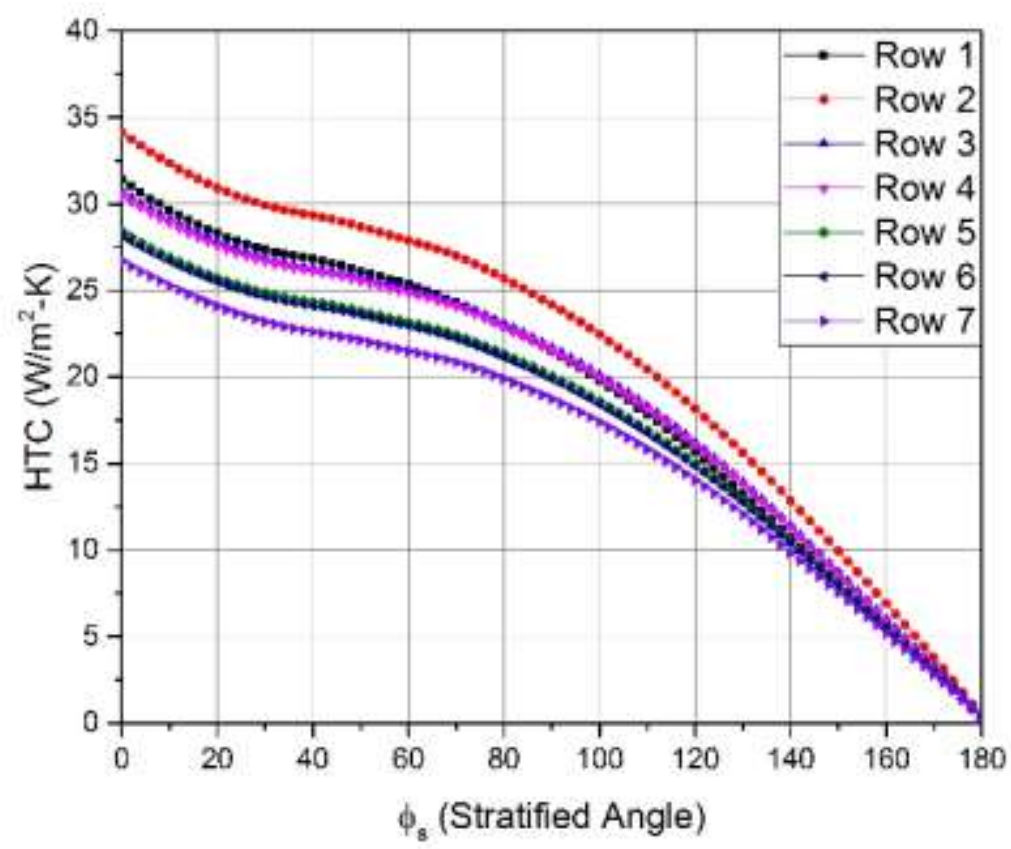

FIG. 19 Dependence of heat transfer coefficient on the stratified angle for $\mathrm{Re}=2000$ in staggered configuration. 
The relationship between the overall heat transfer coefficient and the stratified angle is shown in Figs. 18 and 19 for $\mathrm{Re}=2000$ and a longitudinal pitch of $30 \mathrm{~mm}$. As the condensed liquid accumulates in the lower region of the tube, the resistance on the steam side increases and the overall heat transfer coefficient decreases. At lower Reynolds numbers, the local air side convective heat transfer coefficient distribution strongly affects the rate of decrease. At higher air side Reynolds numbers, the air side heat transfer resistance decreases and the film thickness becomes the controlling factor. The film thickness can be used in conjunction with the stratified angle to determine the overall heat transfer coefficient for the system. Figures $20-23$ show the relationships between the overall heat transfer on each tube and the row number (with row one being nearest to the velocity inlet condition and row seven being furthest away).

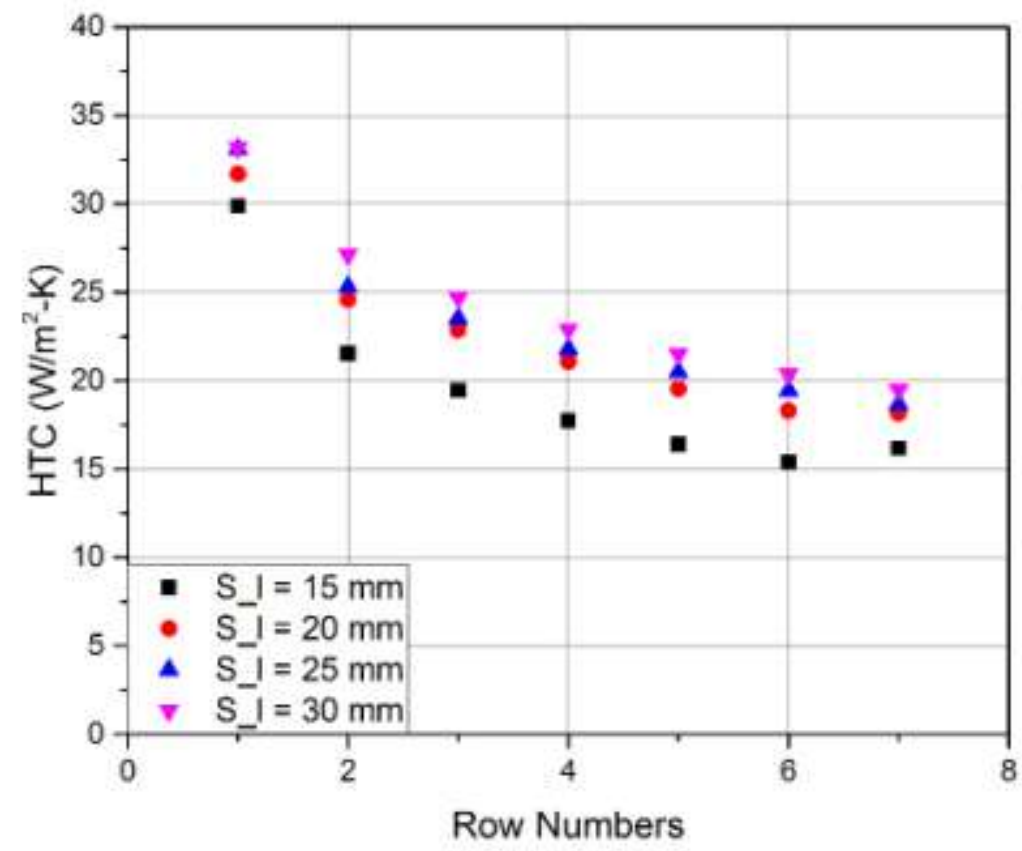

FIG. 20. Dependence of the heat transfer coefficient on the longitudinal pitch for $\operatorname{Re}=2000$ in the inline configuration. 


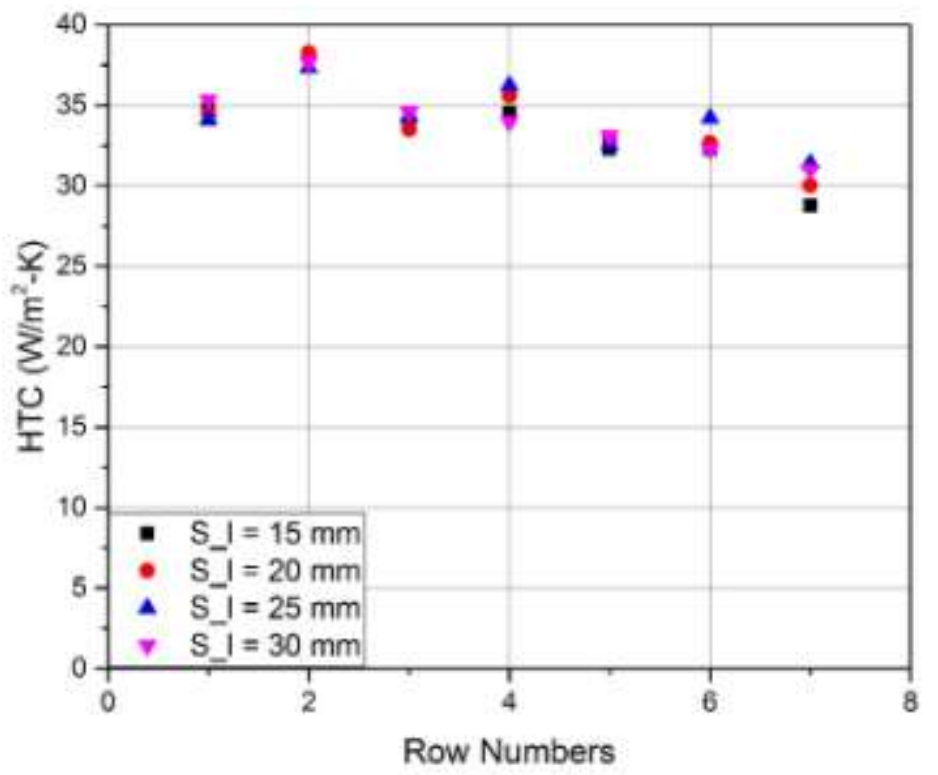

FIG. 21. Dependence of the heat transfer coefficient on the longitudinal pitch for $\operatorname{Re}=2000$ in the staggered configuration.

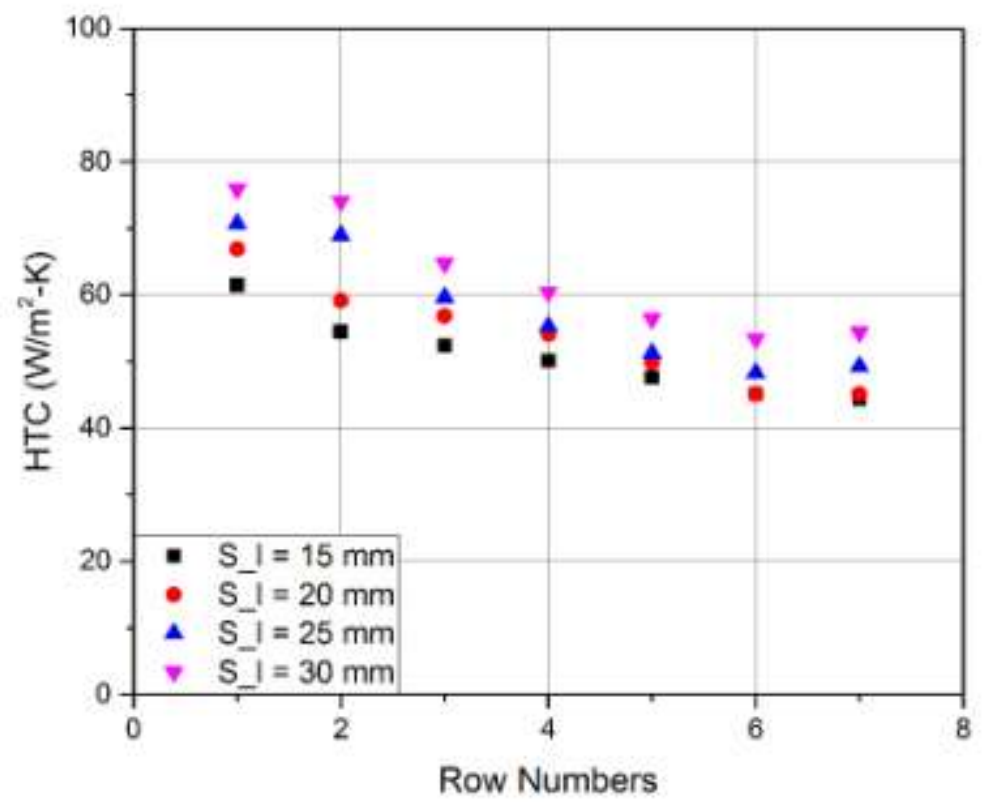

FIG. 22. Dependence of the heat transfer coefficient on the longitudinal pitch for $\mathrm{Re}=5000$ in the inline configuration. 


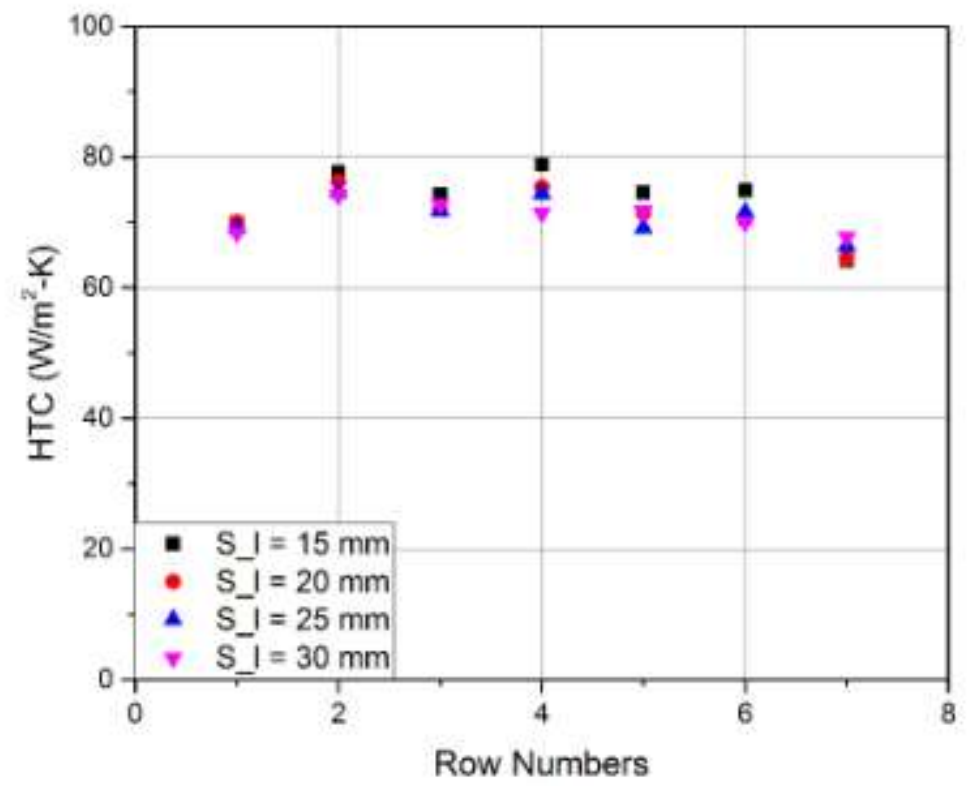

FIG. 23. Dependence of the heat transfer coefficient on the longitudinal pitch for $\operatorname{Re}=5000$ in the staggered configuration.

In the inline configuration, the heat transfer coefficient is largest on the leading cylinder for all the cases with the overall heat transfer coefficient degrading in subsequent rows as the boundary layer develops which increases the local temperatures near the tube surfaces. The staggered configuration show a different trend for both $\mathrm{Re}=2000$ and $\mathrm{Re}=5000$ with a larger heat transfer coefficient on the second tube than on the leading tube due to the flow acceleration due to the blockage by the first row of tubes which is consistent with observations by Buyruk et al. [16]. Studies in the literature have shown that the inclination angle can have a large impact on the overall heat transfer. The inclination angle used for this study was 45 degrees with additional studies needed to optimize this parameter. 


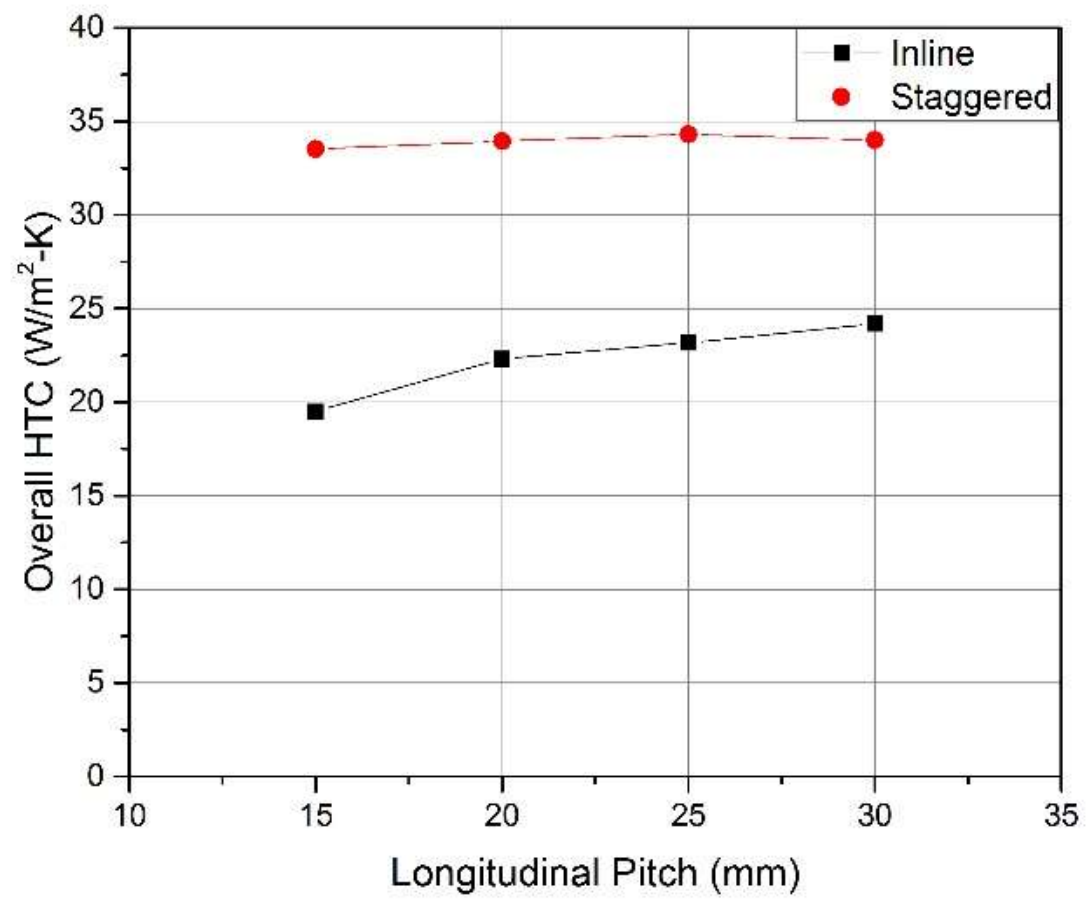

FIG. 24. Dependence of the overall heat transfer coefficient on the longitudinal pitch for $\operatorname{Re}=2000$ in inline and staggered configurations.

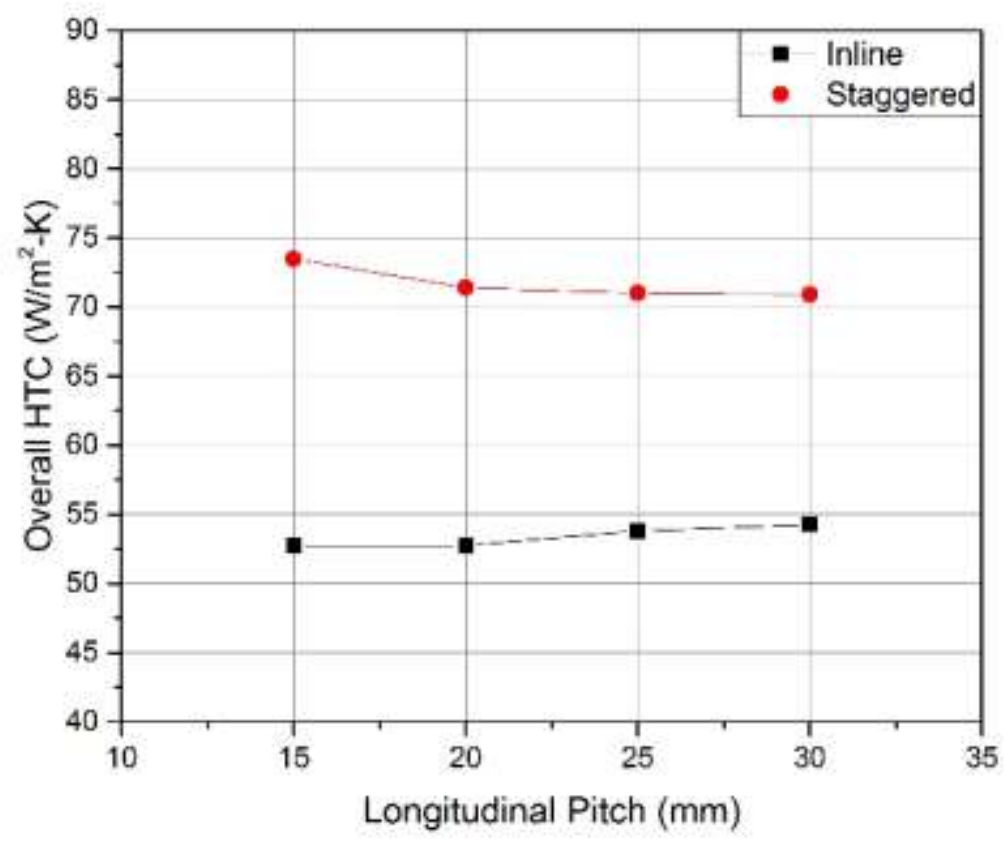


FIG. 25. Dependence of the overall heat transfer coefficient on the longitudinal pitch for $\mathrm{Re}=5000$ in inline and staggered configurations.

Figures 24 and 25 show the dependence of the overall heat transfer coefficient on the longitudinal pitch and the Reynolds number for both configurations. For the lower Reynolds numbers $(\operatorname{Re}=2000)$, the overall heat transfer is strongly dependent on the longitudinal pitch for the inline tube configuration with only a slight improvement being observed as the pitch was increased for the staggered tube configuration. The overall heat transfer coefficient was larger for the higher Reynolds number $(\operatorname{Re}=5000)$ than for the lower Reynolds number.

\section{Conclusions}

The convective cooling of the tube surface by the air side flow in an air cooled condenser was considered to relax the commonly used isothermal boundary condition used in film thickness models. The study investigated the impacts of the coolant Reynolds number, inclination angle, and angle of attack on the film condensation rate. The convective resistance on the outside of the heat exchange tubes is the larger thermal resistance for low air side Reynolds numbers, so the tube wall temperature approaches the saturation temperature of the working fluid. Thus, for low air side Reynolds numbers, the magnitude and direction of the air flow have greater effects on the condensation rate than the film condensation thickness. The inclination angle also significant affects the condensation rate due to the accumulation of condensate at the lowermost point of the tube with the optimal angle varying with the coolant Reynolds number.

The study also analyzed the impact of the tube bundle arrangement on the local film thickness and the overall heat transfer coefficient in the condenser. The overall heat transfer coefficient was determined for each plain tube individually and then for each row. For both $\mathrm{Re}=2000$ and $\mathrm{Re}=5000$, the staggered arrangement gave better condensation rates than the inline arrangement with more uniform overall heat transfer coefficients on the subsequent rows. The back pressure and even back flow caused by pressure differences along adjacent tubes can cause large variations in the heat transfer between rows which will reduce the condensation rate. Thus, the pressure drops must be carefully considered in the design.

While the flow and heat transfer is typically limited by the air side convective cooling in the system, the monitoring of the film condensation on the interior surface of the heat exchanger tubes can yield valuable insight into the added resistance in the axial direction along the cylinder. For future studies of the effects of enhanced air-side heat transfer designs may show that the film thickness plays a larger role in the overall heat transfer in such designs. 


\section{Nomenclature}

D

E

g

$\mathrm{h}$

$\mathrm{H}$

HTC

$\mathrm{Ja}=\mathrm{C}_{\mathrm{p}}\left(\mathrm{T}_{\text {sat }}-\mathrm{T}_{\mathrm{w}}\right) / \mathrm{H}$

$\mathrm{L}$

$\dot{\mathrm{m}}$

$\mathrm{Nu}=\mathrm{hd} / \mathrm{k}$

$\mathrm{p}$

Pr

$\mathrm{r}$

$\mathrm{Ra}=\rho_{\mathrm{l}}\left(\rho_{\mathrm{l}}-\rho_{\mathrm{v}}\right) \mathrm{gD}^{3} \mathrm{C}_{\mathrm{p}} / \mu \mathrm{k}$

$\operatorname{Re}=\rho u d / \mu$

$\mathrm{S}_{\mathrm{t}}$

$\mathrm{S}_{\mathrm{l}}$

$\mathrm{t}$

$\mathrm{T}$

$\mathrm{u}, \mathrm{v}, \mathrm{w}$

$\mathrm{V}$

$\mathrm{x}, \mathrm{y}, \mathrm{z}$
Diameter, $\mathrm{m}$

Total energy, J

Gravity, $\mathrm{m} / \mathrm{s}^{2}$

Convective heat transfer coefficient, $\mathrm{W} / \mathrm{m}^{2} \cdot \mathrm{K}$

Latent heat, $\mathrm{kJ} / \mathrm{kg}$

Overall heat transfer coefficient, $\mathrm{W} / \mathrm{m}^{2} \cdot \mathrm{K}$

Jakob number

Length, $\mathrm{m}$

Mass flow rate, $\mathrm{kg} / \mathrm{s}$

Nusselt number

Pressure, $\mathrm{Pa}$

Prandtl number

Conductivity ratio $\left(\lambda_{\mathrm{a}} / \lambda_{1}\right)$

Rayleigh number

Reynolds number

Transverse pitch, mm

Longitudinal pitch, $\mathrm{mm}$

Time, $\mathrm{s}$

Temperature, $\mathrm{K}$

Velocity components, $\mathrm{m} / \mathrm{s}$

Volume, $\mathrm{m}^{3}$

Spatial coordinates 


\section{Subscripts}

a

$\mathrm{amb}$

eff

$\mathrm{i}, \mathrm{j}, \mathrm{k}$

1

$\mathrm{s}$

sat

v

W

\section{Greek}

$\alpha$

$\beta$

$\delta$

$\rho$

$\lambda$

$\mu$

$\phi$

$\theta$

$\tau$
Air-side
Ambient
Effective
Indices
Liquid
Stratified
Saturation
Vapor
Wall

\author{
Attack angle \\ Inclination angle \\ Film thickness, m \\ Density, kg/m ${ }^{3}$ \\ Thermal conductivity, $\mathrm{W} / \mathrm{m} \cdot \mathrm{K}$ \\ Dynamic viscosity, $\mathrm{kg} / \mathrm{m} \cdot \mathrm{s}$ \\ Film peripheral angle \\ Air-side angle \\ Shear, $\mathrm{Pa}$
}




\section{ACKNOWLEDGMENTS}

This material is based upon work financially supported by the U.S. National Science Foundation under Grant No. IIA-1301726

\section{REFERENCES}

[1] W. Nusselt, "Die Oberflachenkondesation des Wasserdamffes," Zetrschr. Ver. Deutch. Ing., vol. 60, pp. 541-546, 1916.

[2] G. P. Fieg and W. Roetzel, "Calculation of laminar film condensation in/on inclined elliptical tubes," Int. J. Heat Mass Transf., vol. 37, no. 4, pp. 619-624, 1994.

[3] J. C. Chato, "Laminar condensation inside horizontal and inclined tubes," ashrae J., vol. 4, pp. 52-60, 1962.

[4] B. Wang and X. Du, "Study on laminar film-wise condensation for vapor flow in an inclined small / mini-diameter tube," Int. J. Heat Mass Transf., vol. 43, pp. 1859-1868, 2000.

[5] S. B. Memory, W. C. Lee, and J. W. Rose, "Forced convection film condensation on a horizontal tube-effect of surface temperature variation," Int. J. Heat Mass Transf., vol. 36, no. 6, pp. 1671-1676, 1993.

[6] G. E. Karniadakis, "Numerical simulation of forced convection heat transfer from a cylinder in crossflow," Int. J. Heat Mass Transf., vol. 31, no. 1, pp. 107-118, 1988.

[7] V. T. Morgan, "The Overall Convective Heat Transfer from Smooth Circular Cylinders," Adv. Heat Transf., vol. 11, no. C, pp. 199-264, 1975.

[8] W. A. Khan, J. R. Culham, and M. M. Yovanovich, "Fluid flow around and heat transfer from an infinite circular cylinder," $J$. Heat Transf. Asme, vol. 127, no. 7, pp. 785-790, 2005.

[9] M. S. Mon and U. Gross, "Numerical study of fin-spacing effects in annular-finned tube heat exchangers," Int. J. Heat Mass Transf., vol. 47, no. 8-9, pp. 1953-1964, 2004.

[10] K. M. Krall and E. R. G. Eckert, "Local Heat Transfer around a Cylinder at Low Reynolds Number," J. Heat Transfer, vol. 95, no. 2, p. 273, 1973.

[11] W. Chun and R. F. Boehm, "Calculation of Forced Flow and Heat Transfer Around a Cylinder in Crossflow," Numer. Heat Transf. Part A Appl., vol. 15, no. 1, pp. 101-122, 1989.

[12] D. A. Van Meel and T. Hague, "A method for the determination of local convective heat transfer from a cylinder placed normal to an air stream," vol. 5, pp. 715-722, 1962.

[13] V. Yakhot and S. A. Orszag, "Renormalization group and local order in strong turbulence," Nucl. Phys. B (Proceedings Suppl., vol. 2, no. C, pp. 417-440, 1987.

[14] Zukauskas A. Heat transfer from tubes in cross-flow. Adv Heat Transfer 1987;18:87

[15] A. Mirabdolah Lavasani, H. Bayat, Numerical study of pressure drop and heat transfer from circular and cam-shaped tube bank in cross-flow of nanofluid, Energy Convers. Manag. 129 (2016) 319-328.

[16] E. Buyruk, "Numerical study of heat transfer characteristics on tandem cylinders, inline and staggered tube banks in crossflow of air", Int. Commun. Heat Mass Transf. 29 (2002) 